\title{
Tuberculosis infection control knowledge and attitudes among health workers in Uganda: a cross-sectional study
}

\author{
Esther Buregyeya ${ }^{1 *}$, Simon Kasasa ${ }^{1}$ and Ellen M. H. Mitchell ${ }^{2}$
}

\begin{abstract}
Background: The World Health Organization recommends TB infection control (TBIC) in health care facilities. In 2008, the Ministry of Health Uganda initiated efforts to implement TBIC by training of health care workers (HCWs). This study was carried out to assess knowledge and attitudes towards TBIC among HCWs.

Methods: We conducted a cross-sectional study among HCWs in health facilities in the districts of Mukono and Wakiso in Uganda, from October 2010 to February 2011. We assessed HCWs' knowledge of basic standards of TB diagnosis, treatment and TBIC and attitudes towards TBIC measures.

Results: Twenty four percent of the participants answered correctly all the basic TB knowledge questions. Overall, $62 \%$ of the HCWs were judged to have adequate basic TB knowledge. At multivariable analysis, non-clinical cadres, were more likely to have poor basic TB knowledge, [adjusted odds ratio (aOR) $0.43 ; 95 \%$ confidence interval (Cl) 0 . 27-0.68)]. Only $7 \%$ of the respondents answered all the questions on TBIC correctly. Almost all the respondents (98\%; 529/541) knew that TB was transmitted through droplet nuclei, while only a third (34\%; 174/532) knew that masks do not protect the wearer from getting TB. Overall, $69 \%$ (355/512) of the HCWs were judged to have adequate TBIC knowledge. At multivariable analysis, non-clinical cadres (aOR 0.61; $95 \% \mathrm{Cl} 0.38-0.98$ ) and having not attended TBIC training, (aOR 0.65; $95 \% \mathrm{Cl} 0.42-0.99$ ), were more likely to have poor TBIC knowledge. More than three quarters (77\%; 410/530) and $63 \%$ (329/522) of the respondents had a high self-efficacy and perceived threat of acquiring TB at work, respectively. Having not attended a TBIC training was significantly associated with a low self-efficacy (aOR 0.52; $95 \% \mathrm{Cl} 0.33-0.81$ ) and low perceived threat of acquiring TB infection at work, (aOR 0.54; $95 \% \mathrm{Cl} 0.36-0.81)$.
\end{abstract}

Conclusions: Our study finds moderate number of HCWs with correct knowledge and attitudes towards TBIC. Efforts should be put in place to train all HCWs in TBIC, with particular emphasis on the non-clinical staff due to their limited grasp of TBIC measures.

Keywords: Knowledge about TB infection control, Attitudes towards TB infection control, Health workers, Uganda

\section{Background}

Transmission of tuberculosis (TB) to both patients and health care workers (HCWs) in health care settings has been reported from nearly every country, irrespective of local TB incidence $[1,2]$. Transmission usually occurs from undiagnosed or inappropriately treated TB [3]. The risk for transmission varies by setting, occupational

\footnotetext{
* Correspondence: eburegyeya@musph.ac.ug

${ }^{1}$ Makerere University College of Health Sciences, School of Public Health,

Kampala, Uganda

Full list of author information is available at the end of the article
}

group, local prevalence of $\mathrm{TB}$, patient population, and TB infection control (TBIC) measures in health care facilities [4-6]. TB has long been known as occupational hazard among HCWs $[2,4,7]$. Specific groups are at disproportionate risk including morgue technicians, housekeeping staff, laboratory workers [8]. The key factors facilitating nosocomial TB transmission include: delayed diagnosis, ineffective treatment of patients, and lack or inadequate TBIC measures $[3,9]$.

Uganda is among 22 countries with a high burden of TB. Multi-drug resistant TB (MDR-TB) accounts for 
1.4 \% among new patients and $12 \%$ among retreatment $[1,10]$. According to the WHO Global Report 2014, TB treatment success is $77 \%$ [1]. Studies from Uganda found a high burden of TB among hospital staff, with a prevalence of $57 \%$ for latent TB infection (LTBI), and $1.7 \%$ compared to $0.3 \%$ in the general population for active TB [11]. In addition, a high prevalence of LTBI was reported among medical students in Uganda [12]. The WHO recommends TBIC in health care institutions based on four levels: managerial, administrative, environmental and personal protective [3]. These measures have been found to minimize TB transmission [13, 14]. Therefore, it is recommended that all health facilities caring for TB patients or people presumed to have TB, implement TBIC [3]. In 2008, the Ministry of Health Uganda $(\mathrm{MOH})$ and the Tuberculosis Assistance Programme (TBCAP) initiated efforts to implement TBIC by training of HCWs in selected districts, including Mukono district. In addition, the Uganda Ministry of Health produced TBIC guidelines [15] and rolled out the training in other districts in 2011.

Correct knowledge of a health problem, accompanied by the right attitude towards prevention, may result in healthy practices and behaviour $[16,17]$. Previous research among HCWs in other countries has found that HCWs often lack knowledge about $\mathrm{TB}$ and infection control, which contributes to their increased risk [5]. This study was carried out to assess knowledge and attitudes towards TBIC among HCWs, in order to identify barriers to TBIC practices and to pinpoint specific groups who would benefit from mentoring and support on TBIC.

\section{Methods}

\section{Study design, setting and population}

We conducted a cross-sectional study among HCWs in health facilities in the districts of Mukono and Wakiso in central Uganda, from October 2010 to February 2011. These two districts surrounding Kampala, the capital city are semi-urban but predominantly rural. The HIV prevalence among the general population is estimated at $12.5 \%$ among women and $8.4 \%$ among men in Mukono and Wakiso [18]. In the two districts, training in TBIC was conducted 1-2 years preceding this survey. Health care in Uganda is provided by both public and private sector (private-not-for-profit - PNFP and private for profit). Uganda has a decentralised public health care system. At the lowest level is the Village Health Committee which acts as an outpost for outreach services at the village level, followed by health centre (HC) II at parish level (serving about 5000 people), HC III at a sub-county level (serving about 25,000 people), HC IV at the sub-district level (about 100,000 people) and the District Hospital. Each level offers services that the lower level provides in addition to services for its own level. TB services are offered at HC IIIs and above. For the purpose of this study, only public and PNFP health facilities from sub-county health facility (HC III) to hospital level (excluding those located on islands because of accessibility challenges) were included in the study. This is because TBIC training had only been conducted in the public and PNFPs health facilities. In Mukono district, the training was carried out by TBCAP, while in Wakiso district, the $\mathrm{MOH}$ Uganda did the training using the same training materials, with different facilitators and support. The objectives of the training in both districts were to teach HCWs a) how to conduct a TBIC assessment in a health facility and b) to develop and implement a TBIC plan in their facilities. Health facilities were asked to send to two people (usually a TB focal person and a laboratory technician) to attend the training. The trained individuals were supposed to transfer what they learnt to other HCWs through continuous medical education (CMEs) sessions in their respective health facilities. These CMEs are mainly geared towards (and attended by) HCWs who are directly involved in the management of patients.

\section{Sample size and sampling}

A list of all health facilities within each district and the list of HCWs were obtained from the district health offices. Fifty-two health facilities were included in the study and the number of respondents from each health facility was proportional to the size of the facility in order to guarantee an equal probability of selection. HCWs were stratified by cadre in order to obtain a proportional representation of each staff category (doctors, clinical officers, nursing, midwifery, nursing aid, laboratory and radiographers). However, in facilities without all cadres represented, simple random sampling of all the HCWs in that facility was done. HCWs who were not present on the day of the study, for any reason were excluded from the study. Our calculated sample size was 551 HCWs. Full details of the methodology, including sample size calculation can be found in our previous publication [19].

\section{Data collection}

A pre-tested self-administered questionnaire was used to collect data. We evaluated health workers' knowledge of basic standards of TB diagnosis, and treatment as well as TBIC (knowledge about TBIC measures such as use of masks/respirators, triaging and ventilation) and attitudes towards TBIC measures. The questionnaire consisted of 20 questions in total, 7 for basic TB knowledge, 7 for knowledge on TBIC and 6 for attitudes towards TBIC. All the knowledge questions were true/false/ don't know options ('do not know' answers were scored as 
Table 1 Socio-demographic characteristics of the respondents in Mukono and Wakiso districts

\begin{tabular}{|c|c|c|c|c|c|}
\hline \multirow{2}{*}{$\begin{array}{l}\text { Variable } \\
\text { District }\end{array}$} & $\mathrm{n} / \mathrm{N}(\%)$ & \multicolumn{2}{|l|}{ Question } & $\mathrm{n} / \mathrm{N}$ & Percentage (\%) \\
\hline & & \multicolumn{4}{|l|}{ Basic TB knowledge } \\
\hline Mukono & 275/543 (51 \%) & \multirow{2}{*}{$\begin{array}{l}\text { TB is the most common } \\
\text { opportunistic infection } \\
\text { affecting PLWHA }\end{array}$} & Yes & $515 / 5415$ & 95 \\
\hline Wakiso & 268/543 (49 \%) & & No & $26 / 54$ & 5 \\
\hline \multicolumn{2}{|l|}{ Facility level } & \multirow{2}{*}{$\begin{array}{l}\text { HIV infection increases } \\
\text { the risk of developing TB }\end{array}$} & Yes & $527 / 541$ & 97 \\
\hline Hospital & 253/543 (47 \%) & & No & $14 / 541$ & 3 \\
\hline HCIV & 119/543 (22 \%) & \multirow{2}{*}{$\begin{array}{l}\text { There is no difference } \\
\text { between TB infection } \\
\text { and TB disease }\end{array}$} & Yes & $222 / 533$ & 42 \\
\hline HC III & 171/543 (31 \%) & & No & $311 / 533$ & 58 \\
\hline Facility ownership & $351 / 543(65 \%)$ & \multirow{3}{*}{$\begin{array}{l}\text { A patient with suspected } \\
\text { infectious TB should first } \\
\text { be treated with } \\
\text { broad-spectrum antibiotics } \\
\text { before doing any investigations }\end{array}$} & Yes & $192 / 540$ & 36 \\
\hline PNFP & 192/543 (35 \%) & & No & $348 / 540$ & 64 \\
\hline Sex & & & & & \\
\hline Male & 145/538 (27 \%) & \multirow{2}{*}{$\begin{array}{l}\text { The first step in assessing } \\
\text { a TB suspect is to send for } \\
\text { a chest X-ray }\end{array}$} & Yes & $104 / 537$ & 19 \\
\hline Female & 393/538 (73 \%) & & No & $433 / 537$ & 81 \\
\hline \multicolumn{2}{|l|}{ Job category } & \multirow{3}{*}{$\begin{array}{l}\text { Sputum smear microscopy } \\
\text { for AFB (Acid Fast Bacilli) is the } \\
\text { quickest and cheapest way of } \\
\text { identifying infectious TB patients }\end{array}$} & Yes & $510 / 540$ & 94 \\
\hline Doctor & 18/540 (3 \%) & & No & $30 / 540$ & 6 \\
\hline Clinical officer & $75 / 540(14 \%)$ & & & & \\
\hline Registered nurse & $83 / 540(16 \%)$ & \multirow{3}{*}{$\begin{array}{l}\text { All patients who have suspected } \\
\text { infectious TB for the second time } \\
\text { should have a sputum sent for } \\
\text { culture and susceptibility testing }\end{array}$} & Yes & $414 / 535$ & 77 \\
\hline Enrolled nurse & $115 / 540$ (21 \%) & & No & $121 / 535$ & 23 \\
\hline Midwife & 75/540 (14 \%) & & & & \\
\hline Lab staff & 69/540 (13\%) & \multicolumn{4}{|l|}{ TBIC knowledge } \\
\hline Nursing assistants & $81 / 540(15 \%)$ & \multirow[t]{4}{*}{ How is TB transmitted? } & Droplet & $529 / 541$ & 98 \\
\hline Others & 19/540 (4 \%) & & Utensils & $12 / 541$ & 2 \\
\hline Age & & & and & & \\
\hline $15-24$ & 71/543 (13\%) & & $\begin{array}{l}\text { snaking } \\
\text { hands }\end{array}$ & & \\
\hline $25-34$ & 192/543 (35 \%) & \multirow{3}{*}{$\begin{array}{l}\text { Covering the mouth when } \\
\text { coughing has no effect on } \\
\text { how many TB bacilli are expelled } \\
\text { from an infectious TB Patient }\end{array}$} & Yes & $154 / 535$ & 29 \\
\hline $35-44$ & 129/543 (24 \%) & & No & $381 / 535$ & 71 \\
\hline 44 and above & 151/543 (28 \%) & & & & \\
\hline \multicolumn{2}{|l|}{ Cadre } & \multirow{2}{*}{$\begin{array}{l}\text { TB is more likely to be transmitted } \\
\text { on TB wards as opposed to } \\
\text { out-patient departments }\end{array}$} & Yes & $236 / 538$ & 44 \\
\hline Clinical & 435/540 (81 \%) & & No & $302 / 538$ & 56 \\
\hline Non-clinical & 105/540 (19\%) & \multirow{3}{*}{$\begin{array}{l}\text { Is ventilation important in the } \\
\text { implementation of TB infection } \\
\text { control? }\end{array}$} & Yes & $520 / 538$ & 98 \\
\hline Received training in TBIC & & & No & $18 / 538$ & 2 \\
\hline Yes & 241/534 (45) & & & & \\
\hline No & 293/534 (55) & \multirow{2}{*}{$\begin{array}{l}\text { A TB suspect should be placed } \\
\text { in front of the queue in order } \\
\text { to access services quickly }\end{array}$} & Yes & $348 / 533$ & 65 \\
\hline Department & & & No & $85 / 533$ & 35 \\
\hline Outpatient $^{\mathrm{a}}$ & 456/536 (85 \%) & \multirow{2}{*}{$\begin{array}{l}\text { Surgical masks do not } \\
\text { protect the wearer against } \\
\text { TB infection }\end{array}$} & Yes & $174 / 532$ & 34 \\
\hline Medical ward & $80 / 536$ (15 \%) & & No & $353 / 532$ & 66 \\
\hline \multirow{2}{*}{\multicolumn{2}{|c|}{$\begin{array}{l}\text { aOutpatient included the general outpatient department (OPD), HIV clinic, } \\
\text { laboratory, pharmacy, records, and maternal child health services } \\
\text { Denominators vary for different variables because not all respondents } \\
\text { answered all the questions }\end{array}$}} & \multirow{2}{*}{$\begin{array}{l}\text { Sputum induction puts health } \\
\text { workers at an increased risk } \\
\text { of getting infected with TB }\end{array}$} & Yes & $406 / 533$ & 76 \\
\hline & & & No & $127 / 533$ & 24 \\
\hline
\end{tabular}

incorrect), while those on attitudes were scored on five and three point likert scales, but were collapsed to two. The questions were adapted from the www.ghdonline tbic-baseline-assessment tool version 10 April 82009 with some modifications. One point was awarded for
Table 2 Basic knowledge about tuberculosis and infection control among health workers in Mukono and Wakiso districts

broad-spectrum antibiotics before doing any investigations

a chest X-ray

tum smear microscopy quickest and cheapest way of

All patients who have suspected Allious TB for the second time

TBIC knowledge

How is TB transmitted?

each correct answer. Thus the basic knowledge on basic $\mathrm{TB}$ and TBIC was allocated a minimum score of zero and a maximum of 7 each. Data were also collected on HCWs background characteristics including age, sex, qualifications, level of facility they were working in and 
type of facility in terms of ownership (public or private) and district of origin.

\section{Data management and analysis}

Data were entered in Epi-Info Version 3.2.2 software and cleaned before being exported to STATA version 10 for analysis. Respondents were further categorized into clinical and non-clinical cadres. Clinical cadres included professionally qualified health providers (doctors/pharmacists, clinical officers, midwives, registered and certified nurses), while the rest were classified as non-clinical (nursing assistants and health management information system focal persons). Regarding basic knowledge on TB and TBIC, composite variables were created for each. These two variables were the outcome variables, while the explanatory ones were, age, sex, cadre, level of facility, district where the facility is located and ownership of the facility. For each outcome variable we computed a total score for every participant on the attributes, then the percentage by multiplying the total score by $100 \%$. Respondents answering $>85 \%$ of the basic TB knowledge questions were considered to have good basic TB knowledge and others poor knowledge. Those answering $>70 \%$ of the TBIC knowledge questions were considered to have good TBIC knowledge and others poor knowledge. We used a lower cut off for TBIC knowledge ( $>70 \%)$ compared to $>85 \%$ for basic TB knowledge, because TBIC is a new concept and not many of the HCWs may know it compared to basic TB knowledge.

Regarding attitudes towards TBIC, two separate composite variables were created; HCWs' self-efficacy and HCWs' perceived threat of acquiring LTBI at work. HCWs' self-efficacy composed of the following three questions; i) There are things that I can do as a health

Table 3 Bivariate and multivariable analysis of basic knowledge of TB among health care workers in Wakiso and Mukono districts in Uganda

\begin{tabular}{|c|c|c|c|c|c|}
\hline \multirow[t]{2}{*}{ Variable } & \multicolumn{2}{|c|}{ Basic knowledge of TB } & \multirow{2}{*}{$\begin{array}{l}\text { Univariate analysis } \\
\text { Crude OR } 95 \% \text { Cl }\end{array}$} & \multirow{2}{*}{$\begin{array}{l}\text { Multivariate analysis } \\
\text { Adjusted OR } 95 \% \mathrm{Cl}\end{array}$} & \multirow[t]{2}{*}{$P$} \\
\hline & Good & Poor & & & \\
\hline \multicolumn{6}{|l|}{ District } \\
\hline Mukono & 168/255 (66) & $87 / 255$ (34) & 1 & 1 & \\
\hline Wakiso & 154/262 (59) & 108/262 (41) & $0.73(0.51-1.05)$ & $0.83(0.56-1.24)$ & 0.37 \\
\hline \multicolumn{6}{|l|}{ Sex } \\
\hline Male & 96/138 (70) & $42 / 138(30)$ & 1 & 1 & \\
\hline Female & $226 / 376(60)$ & 150/376 (40) & $0.65(0.43-1.00)$ & $0.72(0.47-1.11)$ & 0.14 \\
\hline \multicolumn{6}{|l|}{ Age } \\
\hline $15-24$ & $39 / 67(58)$ & 28/67 (42) & 1 & - & \\
\hline $25-34$ & 117/185 (63) & $68 / 185(37)$ & $1.23(0.69-2.18)$ & - & \\
\hline $35-44$ & $77 / 124(62)$ & $47 / 124(38)$ & $1.17(0.64-2.15)$ & - & \\
\hline 44 and above & $89 / 141(63)$ & $52 / 141(37)$ & $1.22(0.67-2.22)$ & - & \\
\hline \multicolumn{6}{|l|}{ Facility level } \\
\hline $\mathrm{HCIII}$ & 108/167 (65) & $59 / 167(35)$ & 1 & - & - \\
\hline $\mathrm{HCIV}$ & $66 / 112 /(59)$ & $46 / 112(41)$ & $0.78(0.47-1.28)$ & & \\
\hline Hospital & $148 / 238(62)$ & $90 / 238(38)$ & $0.89(0.59-1.35)$ & - & - \\
\hline \multicolumn{6}{|l|}{ Facility ownership } \\
\hline Government & 208/337 (62) & 129/337 (38) & 1 & - & - \\
\hline PNFP & $114 / 180(63)$ & $66 / 180(37)$ & $1.07(0.73-1.55)$ & - & - \\
\hline \multicolumn{6}{|l|}{ Cadre } \\
\hline Clinical & 278/416 (67) & 138/416 (33) & 1 & 1 & \\
\hline Non-clinical & 43/100 (43) & $57 / 100(57)$ & $0.37(0.23-0.58)$ & $0.43(0.27-0.68)$ & $<0.001$ \\
\hline \multicolumn{6}{|c|}{ Attended TBIC training } \\
\hline Yes & 160/230 (70) & $70 / 230(30)$ & 1 & 1 & \\
\hline No & $160 / 280(57)$ & $120 / 280(43)$ & $0.58(0.40-0.84)$ & $0.70(0.47-1.05)$ & 0.08 \\
\hline \multicolumn{6}{|l|}{ Workplace } \\
\hline In-patient & $49 / 79(62)$ & 30/79 (38) & 1 & - & \\
\hline Outpatient & 272/434 (63) & $162 / 434(37)$ & $1.02(0.62-1.68)$ & - & \\
\hline
\end{tabular}


Table 4 Bivariate and multivariable analysis of TBIC knowledge among health care workers in Wakiso and Mukono districts in Uganda

\begin{tabular}{|c|c|c|c|c|c|}
\hline \multirow[t]{2}{*}{ Variable } & \multicolumn{2}{|c|}{ TBIC knowledge } & \multirow{2}{*}{$\begin{array}{l}\text { Univariate analysis } \\
\text { Crude OR } 95 \text { \% Cl }\end{array}$} & \multirow{2}{*}{$\begin{array}{l}\text { Multivariate analysis } \\
\text { Adjusted OR } 95 \% \mathrm{Cl}\end{array}$} & \multirow[t]{2}{*}{$P$} \\
\hline & Good & Poor & & & \\
\hline \multicolumn{6}{|l|}{ District } \\
\hline Mukono & 188/254 (74) & 66/254 (26) & 1 & 1 & \\
\hline Wakiso & $167 / 258(65)$ & $91 / 258(35)$ & $0.64(0.44-0.94)$ & $0.71(0.47-1.07)$ & 0.10 \\
\hline \multicolumn{6}{|l|}{ Sex } \\
\hline Male & 103/137 (75) & $34 / 137(25)$ & 1 & 1 & \\
\hline Female & 252/372 (68) & $120 / 372(32)$ & $0.69(0.44-1.08)$ & $0.77(0.49-1.23)$ & 0.28 \\
\hline \multicolumn{6}{|l|}{ Age } \\
\hline $15-24$ & 40/63 (63) & 23/63 (37) & 1 & - & \\
\hline $25-34$ & 136/186 (73) & $50 / 186(27)$ & $1.56(0.85-2.87)$ & - & \\
\hline $35-44$ & $87 / 123(71)$ & 36/123 (29) & $1.39(0.73-2.64)$ & - & \\
\hline 44 and above & $92 / 140(66)$ & $48 / 140(34)$ & $1.10(0.59-2.05)$ & - & \\
\hline \multicolumn{6}{|l|}{ Facility level } \\
\hline $\mathrm{HCIII}$ & $112 / 166(67)$ & $54 / 166$ (33) & 1 & - & \\
\hline HCIV & 75/112 (67) & 37/112 (33) & $0.98(0.59-1.63)$ & & \\
\hline Hospital & 168/234 (72) & $66 / 234(28)$ & $1.22(0.79-1.89)$ & - & \\
\hline \multicolumn{6}{|l|}{ Facility ownership } \\
\hline Government & 228/332 (69) & 104/332 (31) & 1 & - & - \\
\hline PNFP & $127 / 180(71)$ & $53 / 180(29)$ & $1.09(0.74-1.62)$ & - & - \\
\hline \multicolumn{6}{|l|}{ Cadre } \\
\hline Clinical & 297/411 (72) & $114 / 411(28)$ & 1 & 1 & \\
\hline Non-clinical & 58/99 (59) & 41/99 (41) & $0.54(0.34-0.86)$ & $0.61(0.38-0.97)$ & 0.04 \\
\hline \multicolumn{6}{|l|}{ Workplace } \\
\hline In-patient & $53 / 75(71)$ & 22/75 (29) & 1 & - & - \\
\hline Outpatient & 299/432 (69) & 133/432 (31) & $0.93(0.54-1.59)$ & & \\
\hline \multicolumn{6}{|c|}{ Attended TBIC training } \\
\hline Yes & 174/225 (77) & $51 / 225(27)$ & 1 & 1 & \\
\hline No & 180/282 (64) & 102/282 (36) & $0.51(0.34-0.76)$ & $0.64(0.42-0.99)$ & 0.047 \\
\hline
\end{tabular}

worker to protect myself from TB, ii) 2 . How much impact do you think you have to influence implementation of LTBI control measures in your facility; and iii) It is my responsibility to help identify TB suspects. "HCWs' perceived threat of acquiring LTBI at work" composed of; i) My risk of contracting TB is NOT the same whether windows are open or closed; ii) There is need to screen health workers for TB; iii) How concerned are you about getting TB at your work. For each outcome variable we computed a total score for every participant on the attributes. These two variables were treated as ordinal variables with " 0 " meaning zero correct answer, "1" meaning one correct answer, "2" meaning two correct answers, and " 3 " meaning three correct answers. However, because of small numbers in the cells of "0" and " 1 " levels, respondents who answered zero to two correct answers were considered to have low self-efficacy/ perceived threat, while those that answered correct all the 3 questions, as high self-efficacy/perceived threat. Bivariate analysis using Chi-square test and odds ratios (OR) were performed for basic TB knowledge, knowledge about TBIC, HCWs' self-efficacy and HCWs' perceived threat of acquiring LTBI at work. Logistic regression was used for multivariable analysis to explore the factors associated with all the four outcome. In addition, TBIC knowledge was used to predict self-efficacy and basic TB knowledge for perceived threat of acquiring B infection at work. Variables with $p<$ 0.2 at bivariate level were included in the multivariable analysis model. An association was considered significant at $P<0.05$.

\section{Results}

General characteristics

543 out of 551 HCWs (98.5 \%) completed the questionnaire. The majority of the respondents (73\%) were 
Table 5 Bivariate and multivariable analysis of HCWs self-efficacy towards TBIC in Wakiso and Mukono districts in Uganda

\begin{tabular}{|c|c|c|c|c|c|}
\hline \multirow[t]{2}{*}{ Variable } & \multicolumn{2}{|c|}{ HCWs Self-efficacy towards TBIC } & \multirow{2}{*}{$\begin{array}{l}\text { Univariate analysis } \\
\text { Crude OR } 95 \% \mathrm{Cl}\end{array}$} & \multirow{2}{*}{$\begin{array}{l}\text { Multivariate analysis } \\
\text { Adjusted OR 95\%Cl }\end{array}$} & \multirow[t]{2}{*}{$P$} \\
\hline & High, (n\%) & Low $(n, \%)$ & & & \\
\hline \multicolumn{6}{|l|}{ District } \\
\hline Mukono & 209/266 (79) & $57 / 266(21)$ & 1 & & \\
\hline Wakiso & $201 / 264(76)$ & $63 / 264(24)$ & $0.87(0.58-1.31)$ & - & \\
\hline \multicolumn{6}{|l|}{ Sex } \\
\hline Male & 108/142 (76) & $34 / 142(24)$ & 1 & & \\
\hline Female & 299/383 (78) & $84 / 383(22)$ & $1.12(0.71-1.77)$ & - & \\
\hline \multicolumn{6}{|l|}{ Age } \\
\hline $15-24$ & $53 / 70(76)$ & $17 / 70(24)$ & 1 & & \\
\hline $25-34$ & 153/192 (80) & $39 / 192(20)$ & $1.25(0.66-2.41)$ & - & \\
\hline $35-44$ & $95 / 124(77)$ & 29/124 (23) & $1.05(0.53-2.08)$ & & \\
\hline 44 and above & 109/144 (76) & $35 / 144(24)$ & $0.99(0.51-1.94)$ & & \\
\hline \multicolumn{6}{|l|}{ Facility level } \\
\hline $\mathrm{HCIII}$ & $129 / 169(76)$ & $40 / 169(24)$ & 1 & & \\
\hline HCIV & $90 / 116(78)$ & $26 / 116(22)$ & $1.07(0.61-1.88)$ & - & \\
\hline Hospital & 191/245 (78) & $54 / 245(22)$ & $1.09(0.69-1.75)$ & & \\
\hline \multicolumn{6}{|l|}{ Facility ownership } \\
\hline Government & 263/344 (76) & $81 / 344(24)$ & 1 & & \\
\hline PNFP & 147/186 (79) & $39 / 186(21)$ & $1.16(0.75-1.78)$ & - & \\
\hline \multicolumn{6}{|l|}{ Cadre } \\
\hline Clinical & $338 / 425(80)$ & $87 / 425(20)$ & 1 & 1 & \\
\hline Non-clinical & 70/102 (69) & $32 / 102(31)$ & $0.56(0.34-0.91)$ & $0.63(0.38-1.04)$ & 0.07 \\
\hline \multicolumn{6}{|l|}{ Workplace } \\
\hline In-patient & $60 / 78(77)$ & 18/78 (23) & 1 & & \\
\hline Out-patient & $345 / 445(78)$ & $100 / 445(22)$ & $1.03(0.58-1.83)$ & - & \\
\hline \multicolumn{6}{|c|}{ Attended TBIC training } \\
\hline Yes & 197/232 (85) & $35 / 232(15)$ & 1 & 1 & \\
\hline No & 209/292 (72) & $83 / 292(23)$ & $0.44(0.28-0.69)$ & $0.52(0.33-0.81)$ & $<0.01$ \\
\hline \multicolumn{6}{|l|}{ TBIC knowledge } \\
\hline Poor & $111 / 155(72)$ & 44/155 (28) & 1 & 1 & \\
\hline Good & 276/347 (80) & $71 / 347(20)$ & $1.54(0.99-2.38)$ & $1.27(0.81-2.00)$ & 0.29 \\
\hline
\end{tabular}

females. The mean age of the respondents was 35.6 (10 standard deviation) years and median of 34 years [interquartile range (IQR) 27 to 43]. Over $80 \%$ of the respondents belonged to the clinical cadre, as opposed to non-clinical. Among the clinical cadre, the majority were nurses (51\%), Table 1 . The majority of the respondents worked in outpatient department (i.e., general outpatient department, maternal and child health services, pharmacy, HIV/ART clinic and laboratory). Less than half $(45 \% ; 241 / 534)$ of the participants reported attending a TBIC training, with a significant difference by cadre (clinical and non-clinical; $p=0.002$ ).

\section{Basic TB knowledge and determinants}

The majority of the respondents (95\%; 515/541) knew that TB is the most common opportunistic infection affecting people living with HIV infection. Almost all (97 \%; 527/541) of the respondents were aware that HIV increases the risk of developing TB disease, Table 2. The minimum knowledge score attained by the HCWs was 2 (28.5\%) of the expected maximum of 7 (100\%), with a median of $6(85.7 \%$; IQR $=14.3)$. Twenty four percent $(123 / 517)$ of the participants answered correctly all the questions about basic TB knowledge. Overall, 62 \% (322/ 517 ) of the HCWs were judged to have adequate basic TB knowledge, based on the cut off $>85.7 \%$ (i.e., median 
score). At bivariate analysis, poor basic TB knowledge was significantly associated with female sex (OR 0.65; $95 \%$ CI 0.43-1.00); not attending TBIC training (OR 0.58 ; $95 \%$ CI $0.40-0.84$ ) and being a non-clinical cadre (OR 0.37; 95 \% CI 0.23-0.58). However, basic TB knowledge was not associated with age category, facility ownership, level of facility and where the HCW worked i.e., Wakiso or Mukono district and medical ward or outpatient, Table 3. At multivariable analysis, non-clinical cadres, were more likely to have poor basic TB knowledge, adjusted OR (aOR) 0.43; 95 \% CI 0.27-0.68.

\section{Knowledge about TBIC and determinants}

The minimum score on knowledge about TBIC attained by the respondents was 0 points $(0 \%)$ of the expected maximum 7 points $(100 \%)$, with a median of 5 points $(71 \%$; interquartile range $=28.6)$. Only $7 \%(35 / 512)$ of the respondents answered all the questions on TBIC correctly. Almost all the respondents (98 \%; 529/541) knew that TB was transmitted through droplet nuclei, while a third $(34 \%$; 174/532) knew that masks do not protect the wearer from getting TB, Table 2. Overall, $69 \%(355 / 512)$ of the HCWs were judged to have adequate TBIC knowledge, based on the cut of $>70 \%$. At bivariate analysis, poor TBIC knowledge was significantly associated with coming from Wakiso district (OR 0.64; $95 \%$ CI 0.44-0.94); not attending TBIC training (OR 0.51; $95 \%$ CI 0.34-0.76) and being non-clinical (OR 0.54; 95 \% CI 0.34-0.86). However, knowledge about TBIC was not associated with age category, sex, facility ownership, level of facility and where the HCW worked i.e., medical ward or outpatient, Table 4. At multivariable analysis, being non-clinical (aOR 0.61; $95 \% \mathrm{CI}$ $0.38-0.97)$ and having not attended TBIC training (aOR $0.64 ; 95 \%$ CI $0.42-0.99$ ), were significantly associated with poor TBIC knowledge.

\section{Attitudes towards TB infection control measures Self-efficacy}

Almost all the respondents (97\%; 524/537) felt there are things they could do as HCWs to protect themselves from TB, Table 6 . The majority $(87 \%, 464 / 536)$ reported that they had a moderate capacity to influence the implementation of TBIC in their facilities. More than three quarters $(77 \% ; 410 / 530)$ of the respondents were considered to have a high self-efficacy. At bivariate analysis, being non-clinical cadre (OR 0.56; 95 \% CI 0.34-0.91) and having not attended training in TBIC (OR 0.44; $95 \%$ CI $0.28-0.69)$ were more likely to have a low selfefficacy, Table 5. At multivariable analysis, after controlling for cadre category and knowledge in TBIC, having not attended a TBIC training was significantly associated with a low self-efficacy (aOR 0.52; $95 \%$ CI 0.33-0.81).

\section{Perceived threat of acquiring LTBI at work}

Twenty one percent $(112 / 537)$ of the HCWs mentioned that their risk of contracting TB was the same whether the consultation window was open or closed, Table 6 . Almost two thirds $(63 \% ; 329 / 522)$ of the respondents were considered to have a high perceived threat of acquiring LTBI at work. At bivariate level, a low perceived threat was significantly associated with being female (OR 0.62; $95 \%$ CI 0.41-0.94); having not attended training in TBIC (OR 0.47; $95 \%$ CI 0.33-0.69), and being nonclinician (OR 0.54; 95 \% CI 0.35-0.84), Table 7. At multivariable analysis, not having attended TBIC training was significantly associated with having a low perceived threat of acquiring LTBI at work, (aOR 0.54; $95 \% \mathrm{CI}$ $0.36-0.81)$.

\section{Discussion}

The study assessed HCWs knowledge and attitudes towards TBIC. Twenty four percent (123/517) of the participants answered correctly all the questions about basic TB knowledge. More than half (62 \%) of the HCWs were judged to have adequate basic TB knowledge. Being non-clinical cadre was associated with having poor basic TB knowledge. Additionally, more than two thirds of the HCWs were judged to have adequate TBIC knowledge. Indeed, only $7 \%$ of the respondents answered all the questions on knowledge about TBIC correctly. Knowledge about protection offered by the mask was the lowest with only $34 \%$ of the respondents being aware that surgical masks do not protect the wearer against getting TB. Being a non-clinical cadre and not having attended TBIC training, were associated with having poor TBIC knowledge. Over half of the

Table 6 Attitudes towards TB infection control measures among health care workers in Mukono and Wakiso districts

\begin{tabular}{|c|c|c|c|}
\hline Variable & & $\mathrm{N}$ & Percent \\
\hline \multirow{2}{*}{$\begin{array}{l}\text { There are things that I can do } \\
\text { as a health worker to protect } \\
\text { myself from TB }\end{array}$} & Yes & $524 / 537$ & 98 \\
\hline & No & $13 / 537$ & 2 \\
\hline \multirow{2}{*}{$\begin{array}{l}\text { How much impact do you } \\
\text { think you have to influence } \\
\text { implementation of TB infection } \\
\text { control measures in your facility }\end{array}$} & A lot & $464 / 536$ & 87 \\
\hline & Little/none & $72 / 536$ & 13 \\
\hline \multirow{2}{*}{$\begin{array}{l}\text { It is my responsibility to help } \\
\text { identify TB suspects }\end{array}$} & Very much & $474 / 537$ & 88 \\
\hline & $\begin{array}{l}\text { Somehow/Not } \\
\text { at all }\end{array}$ & $63 / 537$ & 12 \\
\hline \multirow{2}{*}{$\begin{array}{l}\text { My risk of contracting TB is NOT } \\
\text { the same whether windows are } \\
\text { open or closed }\end{array}$} & Yes & $425 / 537$ & 79 \\
\hline & No & $112 / 537$ & 21 \\
\hline \multirow{2}{*}{$\begin{array}{l}\text { There is need to screen health } \\
\text { workers for TB }\end{array}$} & Yes & $447 / 537$ & 83 \\
\hline & No & $90 / 537$ & 17 \\
\hline \multirow{2}{*}{$\begin{array}{l}\text { How concerned are you about } \\
\text { getting TB at your work }\end{array}$} & Concerned & $504 / 529$ & 95 \\
\hline & Not concerned & $25 / 529$ & 5 \\
\hline
\end{tabular}


Table 7 Bivariate and multivariable analysis of perceived threat of acquiring TB infection at work among HCWs in Wakiso and Mukono districts in Uganda

\begin{tabular}{|c|c|c|c|c|c|}
\hline \multirow[t]{2}{*}{ Variable } & \multicolumn{2}{|c|}{ HCWs perceived threat } & \multirow{2}{*}{$\begin{array}{l}\text { Univariate analysis } \\
\text { Crude OR } 95 \% \text { Cl }\end{array}$} & \multirow{2}{*}{$\begin{array}{l}\text { Multivariate analysis } \\
\text { Adjusted OR 95\%Cl }\end{array}$} & \multirow[t]{2}{*}{$P$} \\
\hline & High, (n\%) & Low $(n, \%)$ & & & \\
\hline \multicolumn{6}{|l|}{ District } \\
\hline Mukono & 171/261 (66) & $90 / 261(34))$ & 1 & - & \\
\hline Wakiso & 158/261 (61) & 103/261 (39) & $0.81(0.57-1.15)$ & & \\
\hline \multicolumn{6}{|l|}{ Sex } \\
\hline Male & 100/141 (71) & 41/141 (29) & 1 & 1 & \\
\hline Female & 226/376 (60) & $150 / 376(40)$ & $0.62(0.41-0.94)$ & $0.68(0.44-1.07)$ & 0.09 \\
\hline \multicolumn{6}{|l|}{ Age } \\
\hline $15-24$ & $42 / 68(62)$ & 26/68 (38) & 1 & & \\
\hline $25-34$ & $121 / 186(65)$ & $65 / 186(35)$ & $1.15(0.65-2.05)$ & - & \\
\hline $35-44$ & 77/122 (63) & 45/122 (37) & $1.06(0.57-1.95)$ & & \\
\hline 44 and above & $89 / 146(61)$ & $57 / 146(39)$ & $0.96(0.54-1.75)$ & & \\
\hline \multicolumn{6}{|l|}{ Facility level } \\
\hline $\mathrm{HCIII}$ & 108/168 (64) & 60/168 (36) & 1 & & \\
\hline HCIV & $71 / 116(61)$ & 45/116 (39) & $0.87(0.54-1.43)$ & - & \\
\hline Hospital & 150/238 (63) & $88 / 238(37)$ & $0.95(0.63-1.43)$ & & \\
\hline \multicolumn{6}{|l|}{ Facility ownership } \\
\hline Government & 209/344 (61) & 135/344 (39) & 1 & 1 & \\
\hline PNFP & 120/178 (67) & $58 / 178(33)$ & $1.34(0.91-1.96)$ & $1.28(0.84-1.94)$ & 0.25 \\
\hline \multicolumn{6}{|l|}{ Cadre } \\
\hline Clinical & $277 / 421(66)$ & $144 / 421(34)$ & 1 & 1 & \\
\hline Non-clinical & $50 / 98(51)$ & 48/98 (49) & $0.54(0.35-0.84)$ & $0.63(0.39-1.02)$ & 0.06 \\
\hline \multicolumn{6}{|l|}{ Workplace } \\
\hline In-patient & $50 / 75(67)$ & 25/75 (33) & 1 & - & \\
\hline Out-patient & $273 / 440(62)$ & $167 / 440(38)$ & $0.82(0.49-1.37)$ & & \\
\hline \multicolumn{6}{|c|}{ Attended TBIC training } \\
\hline Yes & 168/230 (73) & $62 / 230(27)$ & 1 & 1 & \\
\hline No & $161 / 286(56)$ & $125 / 286(44)$ & $0.47(0.33-0.69)$ & $0.54(0.36-0.81)$ & $<0.01$ \\
\hline \multicolumn{6}{|c|}{ Basic TB knowledge } \\
\hline Poor & 106/187 (57) & $81 / 187(43)$ & 1 & 1 & \\
\hline Good & 208/311 (67) & 103/311 (33) & $1.54(1.06-2.24)$ & $1.24(0.84-1.86)$ & 0.27 \\
\hline
\end{tabular}

respondents had positive attitudes towards TBIC. Having not attended TBIC training was associated with a low self-efficacy and perceived threat to acquiring $\mathrm{TB}$ at work.

The findings that non-clinical staff and not attending TBIC training tend to have poor basic TB knowledge, TBIC knowledge and poor attitudes towards TBIC (low HCWs' self-efficacy and perceived threat of acquiring LTBI at work), is similar to what was found in the Russian study where physicians and nurses were more knowledgeable than the support staff i.e., non-clinical [20]. This may be attributable to their different educational background and lack of priority for in-service IC trainings. Thus calls for the need to train non-clinical HCWs in TBIC in order to improve their knowledge and attitudes. This is because literature shows a heightened risk of getting TB disease among housekeeping staff [21]. The lower level of knowledge on use of masks is worrying. This is similar to what was found in a study done Ethiopia [22]. Knowledge of TBIC is similar to or higher than what was reported in the Ethiopian study, where $74.4 \%$ of the respondents were found to have good TBIC knowledge [22], while in our study it is $69 \%$. This difference can be explained by a higher cut off of $70 \%$ for our study, compared to the $60 \%$ in the Ethiopian study. 
Not having attended TBIC training was associated with poor TBIC knowledge and attitudes towards TBIC (HCWs' self-efficacy and perceived threat of acquiring LTBI at work). This is consistent with findings from elsewhere that lack of trained staff is a big obstacle to TB control [22, 23]. This raises the importance of training all HCWs in TB and TBIC, i.e., institutionally based and in-service training/continuing education. Well educated HCWs with education needs tailored to job categories is critical for implementation of TBIC measures $[3,20]$. A baseline assessment prior to the training can help identify both the strengths and weaknesses of the HCWs and thus enhance targeted training. Trainings for nursing aids and other lower cadres like cleaners and security guards can be specially arranged at the health facility to focus on their needs and gaps with regard to TBIC.

This study has limitations. We didn't measure the practice of TBIC. Looking at TBIC practice would have given a complete picture. However, this was reported in one of the publications [24], where implementation of TBIC was found to be poor. The strengths of our study was to include all cadres of HCWs both clinical and non-clinical.

\section{Conclusions}

More than half of the respondents were found to have good basic TB knowledge, TBIC knowledge and positive attitudes towards TBIC. Being a non-clinical cadre was associated with poor basic TB knowledge and TBIC knowledge. In addition, not having received training in TBIC was associated with poor TBIC knowledge and attitudes towards TBIC. These gaps in knowledge and attitudes recorded in this study can increase the risk of nosocomial transmission of TB. For effective implementation of TBIC, training in TBIC is critical with support staff (nursing aids, cleaners and security) being prioritized.

\section{Abbreviations}

HCWs, health care workers; MDR-TB, multi drug resistant tuberculosis; SD, standard deviation; TBCAP, Tuberculosis Assistance Programme; TBIC, tuberculosis infection control

\section{Acknowledgements}

We thank the study participants, research assistants, and the district health officials from both districts. We recognize the contribution of Dr. Suzanne Verver (KNCV TB Foundation, Netherlands).

\section{Funding}

We are grateful to KNCV TB Foundation, Netherlands; and the Belgium Technical Corporation (BTC), Belgium for the support.

\section{Availability of data and materials}

Data supporting the findings can be found in the Tables. Addition data that was analysed may be shared upon request.

\section{Authors' contributions}

$\mathrm{EB}$ and $\mathrm{EMH}$ were involved in the development of the proposal. EB carried out field work. EB, EMH and SK undertook data analysis. EB, EMH and SK drafted the manuscript and approved the final draft for publication.

\section{Competing interests}

The authors declare that they have no competing interests.

\section{Consent for publication}

Not applicable.

\section{Ethical approval and consent to participants}

The research protocol was approved by the institutional review board of the Makerere University School of Public Health and the Uganda National Council for Science and Technology (Ref.nr. HS 880). Permission from the incharges of the health facilities was obtained. Informed written consent was obtained from the participants at the time of data collection. Respondents were assured of confidentiality.

\section{Author details}

${ }^{1}$ Makerere University College of Health Sciences, School of Public Health, Kampala, Uganda. ${ }^{2}$ KNCV Tuberculosis Foundation, The Hague, Netherlands.

Received: 6 August 2015 Accepted: 29 July 2016

Published online: 15 August 2016

\section{References}

1. WHO. Global tuberculosis report. Geneva: World Health Organization; 2014

2. Baussano I, et al. Tuberculosis among health care workers. Emerg Infect Dis. 2011;17(3):488-94.

3. WHO. WHO policy on TB infection control in health-care facilities, congregate settings and households. Geneva: World Health Organization; 2009.

4. Menzies D, Joshi R, Pai M. Risk of tuberculosis infection and disease associated with work in health care settings. Int J Tuberc Lung Dis. 2007; 11(6):593-605

5. Jensen PA, et al. Guidelines for preventing the transmission of Mycobacterium tuberculosis in health-care settings, 2005. MMWR Recomm Rep. 2005;54(RR-17):1-141.

6. Jones-Lopez EC, Ellner JJ. Tuberculosis infection among HCWs. Int J Tuberc Lung Dis. 2005;9(6):591.

7. Fennelly KP, Iseman MD. Health care workers and tuberculosis: the battle of a century. Int J Tuberc Lung Dis. 1999;3(5):363-4.

8. Nicol L, et al. A systematic review of the epidemiology of and programmatic response to TB in health care workers in South Africa. 2014

9. Menzies D, et al. Tuberculosis among health care workers. N Engl J Med. 1995;332(2):92-8.

10. Lukoye $D$, et al. Anti-tuberculosis drug resistance among new and previously treated sputum smear-positive tuberculosis patients in Uganda: results of the first national survey. PLoS One. 2013;8(8):e70763.

11. Kayanja HK, et al. Tuberculosis infection among health care workers in Kampala, Uganda. Int J Tuberc Lung Dis. 2005;9(6):686-8.

12. Mugerwa $\mathrm{H}$, et al. High Prevalence of tuberculosis infection among medical students in Makerere University, Kampala: results of a cross sectional study. Arch Public Health. 2013;71(1):7.

13. Basu $\mathrm{S}$, et al. Prevention of nosocomial transmission of extensively drugresistant tuberculosis in rural South African district hospitals: an epidemiological modelling study. Lancet. 2007;370(9597):1500-7.

14. Dharmadhikari AS, et al. Surgical face masks worn by patients with multidrug-resistant tuberculosis: impact on infectivity of air on a hospital ward. Am J Respir Crit Care Med. 2012;185(10):1104-9.

15. $\mathrm{MOH}$. Uganda national guidelines for tuberculosis infection control in health care facilities, congregate settings and households. Kampala: Ministry of Health, Uganda; 2011.

16. Achalu El. Health education concept, method and planning. Lagos: Simarch Nig. Ltd; 2001. p. 91-3.

17. Mirtskhulava $\mathrm{V}$, et al. Determinants of tuberculosis infection control-related behaviors among healthcare workers in the country of Georgia. Infect Control Hosp Epidemiol. 2015;36(5):522-8.

18. MOH. Uganda AIDS Indicator Survey (UAIS). Kampala: Ministry of Health Uganda; 2011. 
19. Buregyeya $\mathrm{E}$, et al. Utilization of HIV and tuberculosis services by health care workers in Uganda: implications for occupational health policies and implementation. PLoS One. 2012;7(10):e46069.

20. Woith WM, Volchenkov G, Larson JL. Russian health care workers' knowledege of tuberculosis. Int J Tuberc Lung Dis. 2010;14(11):1489-92.

21. Ayuk J. A cross-sectional study of tuberculosis among workers in Tygerberg Academic Hospital, Western Cape province, South Africa: Stellenbosch University. Western Cape Province, South Africa: Stellenbosch University; 2013. http://scholar.sun.ac.za/handle/10019.1/85836.

22. Temesgen C, Demissie M. Knowledge and practice of tuberculosis infection control among health professionals in Northwest Ethiopia; 2011. BMC Health Serv Res. 2014;14(1):593.

23. Harries $\mathrm{AD}$, et al. Human resources for control of tuberculosis and HIV-associated tuberculosis. Int J Tuberc Lung Dis. 2005;9(2):128-37.

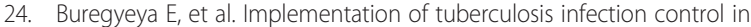
health facilities in Mukono and Wakiso districts, Uganda. BMC Infect Dis. 2013;13:360

Submit your next manuscript to BioMed Central and we will help you at every step:

- We accept pre-submission inquiries

- Our selector tool helps you to find the most relevant journal

- We provide round the clock customer support

- Convenient online submission

- Thorough peer review

- Inclusion in PubMed and all major indexing services

- Maximum visibility for your research

Submit your manuscript at www.biomedcentral.com/submit 